\title{
Announcement
}

\section{CARS 2009}

Computer Assisted Radiology and Surgery

23rd International Congress and Exhibition

Joint Congress of CAR / ISCAS / CAD / CMI /

EuroPACS / CURAC

June 23 - 27, 2009, Berlin, Germany

For information please contact:

CARS Conference Office

Im Gut 15

79790 Kuessaberg, Germany

Tel: +497742922434

Fax: +49 7742922438

E-mail: office@cars-int.org

http://www.cars-int.org

Deadline for submission of abstracts/papers: January 10, 2009

For further information, please refer to our website:

http://www.cars-int.org/ or contact us at office@ cars-int.org. 